\title{
AVALIAÇÃO DAS CONDIÇÕES MICROBIOLÓGICAS EM UNIDADES DE ALIMENTAÇÃO E NUTRIÇÃO
}

\author{
NÉLIO JOSÉ DE ANDRADE ${ }^{1}$ \\ ROSÁLIA MARIA MOREIRA DA SILVA ${ }^{2}$ \\ KELLY CRISTINA SILVA BRABES ${ }^{3}$
}

\begin{abstract}
RESUMO - O presente trabalho é referente a 17 visitas técnicas realizadas em 12 unidades de alimentação e nutrição, cujas produções variam de 1.000 a 4.000 refeições/dia. Foram avaliadas as microbiotas do ar de 63 ambientes diferentes de processamento, as das mãos de 68 manipuladores e as das superfícies de 36 equipamentos e utensílios. Considerando a recomendação da American Public Health Association (APHA), de 30 UFC $/ \mathrm{cm}^{2} / \mathrm{semana}$, apenas $18,5 \%$ e $32,8 \%$ dos ambientes avaliados encontravam-se adequadamente higienizados, em relação ao número de microrganismos aeróbios mesófilos e de fungos filamentosos e leveduras, respectivamente. Para os manipuladores, foram previamente definidas as seguintes faixas de contagens microbianas: até 100; entre 101 e 1.000; entre 1.001 e 10.000 ; entre 10.001 e 100.000 e acima de 100.000 , expressas em UFC/mão. Para os microrganismos mesófilos aeróbios, foram encontrados os seguintes percentuais nas diversas faixas: 11,$7 ; 20,6 ; 35,3 ; 19,2$ e 13,2. Para os coliformes totais: 54,$4 ; 26,5 ; 13,2 ; 5,90$ e 0,00 . Para os fungos fi-
\end{abstract}

lamentosos e leveduras: 63,$4 ; 20,6 ; 12,50 ; 13,5$ e 0,00 . Para Staphylococcus aureus: 71,9; 12,50; 15,6; 0,00 e 0,00 . Por meio de alguns resultados, revela-se a ineficiência nos procedimentos de higienização pessoal. Nos equipamentos e utensílios, os resultados para microrganismos mesófilos aeróbios mostraram que apenas 18,6\% apresentavam-se dentro da recomendação da APHA (2 $\mathrm{UFC} / \mathrm{cm}^{2}$ ). Usando-se esse mesmo parâmetro, constataram-se os percentuais de 45,6 para coliformes totais e de 44,6 para fungos filamentosos e leveduras de equipamentos e utensílios em condições higiênicas satisfatórias. Fica evidenciada a necessidade de definição de padrões ou recomendações mais adequados às condições brasileiras para o controle microbiológico de ambientes, de manipuladores e de equipamentos e utensílios em unidades de alimentação e nutrição. Nas condições microbiológicas em que se encontram, os restaurantes avaliados devem determinar, numa fase inicial, metas a serem atingidas. Em etapas posteriores, deverão atender a recomendações mais exigentes.

TERMOS PARA INDEXAÇÃO: Avaliação microbiológica, restaurantes industriais, ambientes, manipuladores e equipamentos.

\section{EVALUATION OF MICROBIOLOGICAL CONDITIONS IN FOOD SERVICE STABLISHIMENTS}

\begin{abstract}
The microbiological quality of the air in 63 processing areas, in the hands of 68 manipulator personnel, and on 36 equipments and utensils in food service establishments were evaluated. No more than $19 \%$ and $32 \%$ of the air in processing areas were in good hygienic conditions for mesophilic aerobics, and molds and yeasts, respectively. The number of microorganisms in those areas was below the APHA recommendation, $30 \mathrm{cfu} / \mathrm{cm}^{2} /$ per week. As there is no microbiological specification or recommendation for manipulators, in this study, five ranges of
\end{abstract}

microbiological numbers per hand were established $\left(<10^{2}, 10^{2}-10^{3}, 10^{3}-10^{4}, 10^{4}-10^{5}\right.$, and $>10^{5}$, in cfu per hand. For mesophilic aerobic bacteria, it was determined the following percentages in the different ranges $12,21,35,19$, and $13 \%$, for total coliforms: 54 , $27,13,6$, and $0 \%$, for molds and yeasts: $63,21,13,14$, and $0 \%$, and for $S$. aureus $72,13,16,0$, and $0 \%$. Some results showed an inadequate personal hygiene procedure. For mesophilic aerobics, the results showed that $19 \%$ of the equipment and utensil surfaces were in good hygienic conditions, according to APHA 
recommendations $\left(2 \mathrm{cfu} / \mathrm{cm}^{2}\right)$. Using the same recommendations for total coliforms and molds and yeasts, it could be observed that 46 and $45 \%$ of the surfaces, respectively, were in good hygienic conditions. It was observed that is necessary to establish standards or specifications more adequate to control microbiological conditions in Brazilian food service establishments. Firstly, these establishments should determine goals for microbiological specification to be reached. After that, they should attend harder specifications.

INDEX TERMS: Microbiological evaluation, food service establishments, air of food processing areas, manipulators, equipments and utensils.

\section{INTRODUÇÃO}

De acordo com dados epidemiológicos disponíveis, as unidades de alimentação e nutrição, nas quais estão incluídos os restaurantes industriais, são umas das maiores fontes de surtos de doenças veiculadas por alimentos. As bactérias, os fungos, os vírus, os parasitas, os agentes químicos e as substâncias tóxicas de origens animal e vegetal atuam como agentes etiológicos desses surtos. Não há dúvidas, no entanto, da importância das bactérias como agentes das doenças de origem alimentar. De acordo com o Center For Disease Control nos EUA, elas são responsáveis pela ocorrência de cerca de $70 \%$ dos surtos e $95 \%$ dos casos de toxinfecções alimentares (Buzby et al., 1996).

Com o aumento do número de empresas no setor de refeições coletivas, cujo crescimento é de cerca de $20 \%$ ao ano, aumentam também as perspectivas de ocorrências de toxinfecções alimentares. Atualmente, estima-se que aproximadamente dois bilhões de refeições são produzidas anualmente em cozinhas de grande porte, atendendo a cerca de $28 \%$ da população economicamente ativa (Freitas, 1995).

Para atender à legislação em vigor (Brasil, 2001) e não colocar em risco a saúde dos usuários, com a veiculação de microrganismos patogênicos, deve-se controlar a contaminação, a multiplicação e a sobrevivência microbiana nos diversos ambientes, tais como: equipamentos, utensílios e manipuladores, o que contribuirá para a obtenção de alimentos com boa qualidade microbiológica (Hazelwood, 1994; ABERC, 1995).

Nos aerossóis utilizados nos ambientes de processamento, encontram-se, principalmente, esporos de bactérias e fungos e, ainda, leveduras. Por outro lado, quando os manipuladores são a principal causa da contaminação microbiana desses ambientes, há predominância de formas vegetativas de bactérias, entre as quais estão incluídas as espécies dos gêneros Staphylococcus, Streptococcus, Micrococcus e outros organismos relacionados com o trato respiratório, com a pele e com o cabelo (Sveum et al., 1992; Salustiano et al., 2001).
De acordo com dados da Organização Mundial de Saúde (OMS), os manipuladores são responsáveis direta ou indiretamente por até $26 \%$ dos surtos de enfermidades bacterianas veiculadas por alimentos (Freitas, 1995). Em várias pesquisas, tem-se demonstrado a relação existente entre manipuladores de alimentos e doenças bacterianas de origem alimentar. Podem ser manipuladores doentes, ou portadores assintomáticos, ou que apresentem hábitos de higiene pessoal inadequados, ou ainda que usem métodos anti-higiênicos na preparação de alimentos (Cardoso et al., 1996). Mesmo os manipuladores sadios abrigam bactérias que podem contaminar os alimentos pela boca, nariz, garganta e trato intestinal.

Equipamentos e utensílios com higienização deficiente têm sido responsáveis, isoladamente ou associados a outros fatores, por surtos de doenças de origem alimentar ou por alterações de alimentos processados (Andrade \& Macêdo, 1996). Há relatos de que utensílios e equipamentos contaminados participam do aparecimento de aproximadamente $16 \%$ dos surtos (Freitas, 1995). Cortadores de frios, cortadores de legumes, bandejas, pratos, talheres, tabuleiros, placas de altileno, amaciadores de carne, entre outros, devem passar constantemente por uma avaliação microbiológica para controle da eficiência do procedimento de higienização, evitando-se a contaminação dos alimentos produzidos (Andrade \& Macêdo, 1996).

A atuação dos profissionais responsáveis pela qualidade nas unidades industriais de alimentação e nutrição deve ser eminentemente preventiva. Fundamentado em planos de amostragem bem definidos, o monitoramento por meio da avaliação microbiológica do ambiente, dos equipamentos, dos utensílios e dos manipuladores pode melhorar sensivelmente a qualidade dos alimentos servidos aos usuários (Andrade et al., 2000). Os resultados obtidos com esse monitoramento, normalmente, são comparados às especificações ou às recomendações propostas por órgãos oficiais ou por entidades científicas conceituadas, tais como a American $\mathrm{Pu}$ blic Health Association (APHA) e a Organização Mundial de Saúde (OMS). Dependendo dos resultados, mantêm-se as técnicas de higienização adotadas ou são to- 
madas medidas corretivas. Conduziu-se este trabalho com os objetivos de avaliar as condições microbiológicas de ambientes, mãos de manipuladores, equipamentos e utensílios de restaurantes industriais e estabelecer se as condições atendem às recomendações preconizadas pela APHA, OMS e por pesquisadores.

\section{MATERIAL E MÉTODOS}

Foram efetuadas 17 visitas a 12 restaurantes industriais localizados nas regiões da Zona da Mata e Metalúrgica de Minas Gerais, com capacidade para produção de 1.000 a 4.000 refeições/dia, avaliando-se as condições microbiológicas dos ambientes, dos manipuladores e dos equipamentos e utensílios.

Sessenta e três ambientes de processamento, selecionados pelos responsáveis técnicos dos restaurantes, foram avaliados pela técnica de sedimentação simples (Sveum et al., 1992). Dentre esses, foram incluídas as câmaras frias e as áreas de higienização, as de preparo de saladas, as de recepção e de cocção de alimentos, as de limpeza de arroz e de catação de feijão, as do almoxarifado e as dos salões de refeição. Essa técnica consistiu na exposição, aos ambientes avaliados, de placas de Petri contendo ágar para contagem total (ACT), por 15 minutos, para determinação de microrganismos mesófilos aeróbios e na exposição de batata dextrose ágar (BDA) para determinação de fungos filamentosos e leveduras. Em seguida, as placas foram transportadas para o laboratório e incubadas a $35^{\circ} \mathrm{C}$ por 48 horas e a $25^{\circ} \mathrm{C}$ por 72 horas, respectivamente. A contagem de colônias na placa foi multiplicada por 10 para obter o resultado expresso em Unidades Formadoras de Colônias (UFC) por $\mathrm{cm}^{2}$ por semana.

Sessenta e oito manipuladores, sendo pelo menos quatro de cada restaurante, foram submetidos à avaliação microbiológica. Os microrganismos foram removidos das mãos, consideradas higienizadas, pelos próprios manipuladores. Swabs preparados conforme técnica descrita pela APHA (Sveum et al., 1992) foram usados para remover os microrganismos das mãos dos manipuladores, escolhidos de forma aleatória (Cardoso et al., 1996). A remoção ocorreu numa área correspondente às superfícies da palma e das bordas, partindo da região dos punhos. De forma angular, o swab foi passado, com movimentos giratórios, da parte inferior da palma até a extremidade dos dedos e voltando ao punho, repetindose esse procedimento três vezes na direção de cada dedo. Os movimentos nas bordas foram do tipo vai-e-vem, de modo a avançar em um dos lados da mão onde as linhas dos punhos se iniciavam, passando depois entre os dedos e, no final, no outro lado da mão, encontrando-se de novo com as linhas dos punhos.

Em seguida, os microrganismos aderidos ao swab foram transferidos para tubos de ensaio, contendo $10 \mathrm{~mL}$ de solução Ringer $1: 4$, acrescentada de $0,25 \%$ de tiossulfato de sódio, esterilizada a $121^{\circ} \mathrm{C}$ por $15 \mathrm{minu}$ tos. Usou-se o agente redutor tiossulfato de sódio considerando que os sanificantes químicos usados nos restaurantes industriais eram agentes oxidantes, como cloro, iodo e ácido peracético. Esses frascos foram transportados sob refrigeração para o laboratório para as contagens de microrganismos mesófilos aeróbios (ACT), de coliformes totais (VRB), de fungos e de leveduras (BDA) e de Staphylococcus aureus (Baird-Parker), conforme recomendação da APHA (Sveum et al., 1992), e os resultados foram expressos em UFC/mão.

Trinta e seis equipamentos e utensílios foram avaliados nos diversos restaurantes. Dentre esses, incluíram-se cortadores de frios, cortadores de legumes, máquima de moer carne, placa de altileno, bandejas de refeição, talheres, pratos de louça e liquidificadores. Os microrganismos eram removidos das superfícies consideradas higienizadas pela técnica do swab, conforme recomendação da APHA (Sveum et al., 1992). Para isso, utilizou-se swab de algodão não-absorvente, de $0,5 \mathrm{~cm}$ de diâmetro/ $2 \mathrm{~cm}$ de comprimento, em uma haste de 12 $\mathrm{cm}$ de comprimento. Os swabs foram esterilizados por autoclavagem a $121^{\circ} \mathrm{C}$, por 15 minutos.

Após ser umedecido, o swab foi friccionado, por três vezes, formando um ângulo de $30^{\circ}$ com a superfície, no sentido vai-e-vem, numa área de $2 \times 25 \mathrm{~cm}$ e, em seguida, os microrganismos coletados foram transferidos para tubos de ensaio, 20x250 mm, contendo $10 \mathrm{~mL}$ de solução neutralizante de tiossulfato de sódio a $0,25 \%$ em solução Ringer 1:4, de pH 7,0, esterilizada por autoclavagem a $121^{\circ} \mathrm{C}$ por 15 minutos. Após a imersão, o excesso de solução do swab foi retirado, pressionando-o na superfície do tubo. Esse mesmo swab foi utilizado para coletar microrganismos em outra área de $2 \times 25 \mathrm{~cm}$ do mesmo equipamento e transferidos também para $o$ mesmo tubo de ensaio. Esse procedimento foi repetido por mais três vezes, totalizando uma área de $250 \mathrm{~cm}^{2}$ por equipamento. Quando havia dificuldades para a determinação dessa área nos equipamentos, foram feitas estimativas e as coletas foram efetuadas sempre da mesma forma.

Após a coleta, os tubos foram transportados, sob refrigeração, ao laboratório de microbiologia para as análises de microrganismos mesófilos aeróbios (ACT), de coliformes totais (VRB) e de fungos e leveduras 
(BDA), sendo os resultados expressos em Unidades Formadoras de Colônias (UFC) por $\mathrm{cm}^{2}$ de superfície.

Os resultados foram comparados com as recomendações e especificações estabelecidas pela APHA ou OMS ou propostas por alguns pesquisadores.

\section{RESULTADOS E DISCUSSÃO}

Em função das exigências de qualidade microbiológica dos ambientes, os restaurantes industriais, considerando-se a técnica da sedimentação simples utilizada, podem ser enquadrados na Classe 100.000, conforme recomendação da APHA (Sveum et al., 1992). Nessa classe, os ambientes são considerados em condições higiênicas satisfatórias, adequadas ao processamento de alimentos quando apresentarem uma contagem de microrganismos mesófilos aeróbios de até 30 $\mathrm{UFC} / \mathrm{cm}^{2} / \mathrm{semana}$.

Outras classes, em que as condições de trabalho exigem melhor qualidade microbiológica do ar, são também propostas pela APHA. Por exemplo, a Classe 10.000 é equivalente às condições de um ar condicionado sem fluxo laminar e deve apresentar um máximo de 6 microrganismos mesófilos aeróbios $/ \mathrm{cm}^{2} /$ semana. Já a Classe 100 deve apresentar uma qualidade de ar equivalente a uma sala com fluxo laminar e exige contagens máximas de 1,2 microrganismo mesófilos aeróbios $/ \mathrm{cm}^{2} /$ semana.

Em relação aos microrganismos mesófilos aeróbios, verificou-se que apenas $18,5 \%$ dos ambientes avaliados encontravam-se corretamente higienizados. Usando-se essa mesma recomendação para fungos e leveduras, constatou-se que $32,28 \%$ dos ambientes apresentavam condições satisfatórias de higiene (Quadro 1).

Muitas vezes, essa recomendação americana da APHA pode ser considerada rígida para os restaurantes brasileiros, em razão principalmente das condições de temperatura ambiental. Admitindo-se, por exemplo, contagens de até $100 \mathrm{UFC} / \mathrm{cm}^{2} /$ semana, esses percentuais passariam a 51,8 para microrganismos mesófilos aeróbios e 62,7 para fungos e leveduras (Quadro1).

Foram observadas variações nas contagens microbianas entre os ambientes refrigerados e nãorefrigerados (Quadro 2). Entre os ambientes refrigerados, estão incluídas as câmaras frias de verdura, de carne e de laticínios. Entre os ambientes não-refrigerados, encontram-se as áreas de cocção, de corte de vegetais, de catação de arroz e feijão, de preparo de saladas, de higienização e o salão de refeições. A média do número de microrganismos mesófilos aeróbios para ambientes refrigerados foi de $77 \mathrm{UFC} / \mathrm{cm}^{2} / \mathrm{semana}$; já, para os não refrigerados, foi de $212 \mathrm{UFC} / \mathrm{cm}^{2} /$ semana.

QUADRO 1 - Avaliação microbiológica do ar de 63 ambientes de processamento em unidades de alimentação e nutrição.

\begin{tabular}{|l|c|c|}
\hline \multicolumn{1}{|c|}{ Análise Microbiológica } & $\begin{array}{c}\text { Até 30 UFC/cm2/semana } \\
(\boldsymbol{\%})\end{array}$ & $\begin{array}{c}\text { Até 100 UFC/cm2/semana } \\
(\boldsymbol{\%})\end{array}$ \\
\hline Microrganismos Mesófilos Aeróbios & 18,5 & 51,8 \\
\hline Fungos filamentos e leveduras & 32,3 & 62,7 \\
\hline
\end{tabular}

QUADRO 2 - Números (UFC/cm²/semana) mínimos, médios e máximos de microrganismos mesófilos aeróbios e de fungos filamentosos e leveduras em ambientes refrigerados e não-refrigerados.

\begin{tabular}{|l|c|c|c|c|c|c|}
\hline \multirow{2}{*}{ Análise Microbiológica } & \multicolumn{3}{|c|}{ Ambiente Refrigerado } & \multicolumn{3}{c|}{ Ambiente Não-refrigerado } \\
\cline { 2 - 7 } & Mínimo & Médio & Máximo & Mínimo & Médio & Máximo \\
\hline Microrganismos Mesófilos Aeróbios & 10 & 77 & 400 & 10 & 212 & 3000 \\
\hline Fungos Filamentosos e Leveduras & 10 & 54 & 200 & 100 & 105 & 500 \\
\hline
\end{tabular}


A metodologia analítica usada, que consiste na contagem de partículas (microrganismos) viáveis em uma determinada área por um definido período de tempo, sem dúvida, apresenta várias limitações e, na realidade, indica um nível aproximado de contaminação do ambiente avaliado. É uma técnica classificada como classe D pela APHA, ou seja, uma metodologia que já foi considerada padrão, mas que está sendo substituída por técnicas mais eficientes. Além disso, a técnica de sedimentação simples não recupera alguns tipos de microrganismos presentes no ar. No entanto, é uma técnica recomendada por um órgão reconhecido internacionalmente e, por isso, é útil na avaliação de ambientes nos restaurantes industriais. Deve-se frisar, porém, que as técnicas que avaliam volumes de ar fornecem resultados mais confiáveis. Dentre essas últimas, incluem-se as técnicas da membrana filtrante, precipitador eletrostático e impressão em ágar (Sveum et al., 1992; Salustiano et al., 2001).

A técnica de sedimentação simples permite definir os tipos de microrganismos presentes no ambiente, por meio do uso de meios de cultura apropriados. Por exemplo, além de mesófilos aeróbios e fungos e leveduras, pode-se determinar a ocorrência de coliformes totais e fecais, Staphylococcus aureus, Salmonella spp $e$ Bacillus cereus, entre outros. A definição dos tipos de microrganismos auxilia na escolha do procedimento de higienização mais adequado (Andrade \& Macêdo, 1996), principalmente no que se refere ao agente sanificante, quando medidas corretivas se fizerem necessárias. Por exemplo, se há predominância de fungos e leveduras no ambiente, geralmente recomenda-se aplicação, pelo método spray, de produtos à base de quaternário de amônio. Se predominarem bactérias, pode-se optar por produtos à base de cloro, iodo, ácido peracético e clorhexidina. Neste trabalho, constatou-se a presença de ambos os grupos microbianos, o que sugere, para maior eficiência, um rodízio de agentes químicos.

Verifica-se a necessidade de definição de especificações ou de recomendações mais adequadas às condições brasileiras para o controle microbiológico de ambientes. Provavelmente, nas condições microbiológicas em que se encontram, os restaurantes avaliados devem determinar, numa fase inicial, metas a serem atingidas. Em etapas posteriores, deverão atender a recomendações mais exigentes.

Em relação às mãos de manipuladores, considerando-se a inexistência de padrões ou especificações para contagens microbianas, foram estabelecidas, previamente, faixas de contagens que pudessem servir de orientação para definir suas condições higiênico-sanitárias: até100; entre 101 e 1.000 ; entre 1.001 e 10.000 ; entre 10.001 e 100.000 e acima de 100.000, expressas em UFC/mão (Quadro 3). Dentre as análises efetuadas, as contagens de microrganismos mesófilos aeróbios, de coliformes totais e de fungos e leveduras avaliam as condições higiênicas e as de $S$. aureus revelam as condições higiênico-sanitárias (Brasil, 2001).

Em relação às análises, deve-se considerar o nível de respostas obtidas em função da metodologia usada. Assim, por exemplo, no caso de $S$. aureus, determinam-se índices iguais ou superiores a $100 \mathrm{UFC/mão.} \mathrm{A}$ ausência de crescimento, quando se inocula $0,1 \mathrm{~mL}$ (de $10 \mathrm{~mL}$ ) da amostra coletada, pela técnica do espalhamento superficial, indica contagens $100 \mathrm{UFC/mão.} \mathrm{Esse}$ limite é de 10 UFC/mão, no caso de microrganismos mesófilos aeróbios, de coliformes totais e de fungos e leveduras, em que a metodologia permite inóculo de 1 $\mathrm{mL}$ da diluição 1:10 pela técnica de plaqueamento em profundidade. Os manipuladores apresentaram contagens de microrganismos mesófilos aeróbios mais elevadas, em relação aos demais grupos microbianos. Somente $11,76 \%$ dos manipuladores tinham até $100 \mathrm{UFC/mão}$ de microrganismos mesófilos aeróbios. Os percentuais foram de 54,41; 53,37 e 71,88 para coliformes totais, para fungos e leveduras e para $S$. aureus, respectivamente. Além disso, apenas foram detectadas as contagens superiores a 100.000 UFC/mão para microrganismos mesófilos aeróbios. Para coliformes totais e fungos e leveduras, não foram detectadas contagens superiores a $10.000 \mathrm{UFC} / \mathrm{mão}$, e para $S$. aureus, não superiores a $1.000 \mathrm{UFC} / \mathrm{mão}$. Considerando-se a faixa de até 1.000 UFC/mão, os percentuais foram 67,56; 94,10; 86,43 e 100 para microrganismos mesófilos aeróbios, coliformes totais, fungos e leveduras e $S$. aureus, respectivamente.

Pelos resultados revela-se uma grande variação nas contagens microbianas para os diversos restaurantes avaliados. Isso indica ineficiência nas técnicas de processamento e nos procedimentos de higienização praticados em alguns dos estabelecimentos.

Tais fatos podem originar desde alterações de ordem sensorial nos alimentos produzidos, até possibilidade de ocorrência de toxinfecções alimentares naqueles restaurantes que apresentam elevadas contagens (Girioli, 1993). Esses estabelecimentos, no mínimo, estão operando com grande risco de ocorrência de toxinfecções alimentares causadas por microrganismos. Portanto, os responsáveis técnicos pela qualidade nos restaurantes devem receber treinamento adequado para a 
QUADRO 3 - Avaliação microbiológica de mãos de 68 manipuladores de alimentos em unidades de alimentação e nutrição.

\begin{tabular}{|c|c|c|c|c|c|}
\hline Análises Microbiológicas & $\begin{array}{l}\text { Até } 100 \\
(\%)\end{array}$ & $\begin{array}{cc}\text { Entre } 101 \mathrm{e} \\
1.000 & (\%)\end{array}$ & $\begin{array}{l}\text { Entre 1.001 e } \\
10.000\end{array}$ & $\begin{array}{c}\text { Entre 10.001 e } \\
100.000 \\
(\%)\end{array}$ & $\begin{array}{c}\text { Acima de } \\
100.000 \\
(\%)\end{array}$ \\
\hline $\begin{array}{l}\text { Microrganismos Mesófilos } \\
\text { Aeróbios }\end{array}$ & 11,7 & 20,6 & 35,3 & 19,2 & 13,2 \\
\hline Coliformes totais & 54,4 & 26,5 & 13,2 & 5,9 & 0,0 \\
\hline $\begin{array}{l}\text { Fungos Filamentosos e Leve- } \\
\text { duras }\end{array}$ & 63,4 & 20,6 & 12,5 & 13,5 & 0,0 \\
\hline Staphylococcus aureus & 71,9 & 12,5 & 15,6 & 0,0 & 0,0 \\
\hline
\end{tabular}

função e ser apoiados pela administração geral da empresa. O treinamento significa adquirir conhecimentos nas áreas de processamento, de microbiologia de alimentos, de controle de qualidade e de higienização industrial, entre outras. Com os resultados demonstra-se a necessidade de cada restaurante avaliar as condições higiênico-sanitárias dos manipuladores e, quando necessário, realizar trabalho de conscientização e estabelecer metas a serem atingidas.

No que se refere a equipamentos e utensílios, pelos resultados, verifica-se que apenas $18,6 \%$ dos equipamentos e dos utensílios avaliados apresentaram contagens de microrganismos mesófilos aeróbios até 2 UFC $/ \mathrm{cm}^{2}$ de superfície, conforme recomendação da APHA (Sveum et al., 1992).

Utilizando-se essa mesma recomendação, constataram-se os percentuais de 45,6 para coliformes e 44,6 para fungos e leveduras em equipamentos e utensílios em condições higiênicas satisfatórias. Muitas vezes a recomendação americana é considerada rígida para as condições dos restaurantes brasileiros. Por isso, alguns pesquisadores e algumas instituições admitem contagens de até $50 \mathrm{UFC} / \mathrm{cm}^{2}$ de superfície. Nesse caso, os percentuais de 52,9 para microrganismos mesófilos aeróbios, 76,7 para coliformes totais e 77,1 para fungos e leveduras encontram-se dentro dessa recomendação.

Constatou-se, portanto, que percentuais elevados dos equipamentos e dos utensílios nos restaurantes avaliados não atendiam às recomendações da APHA e nem a outras menos rígidas para microrganismos mesófilos aeróbios. Com esses resultados, demonstra-se que as condições higiênicas dos restaurantes podem e devem ser melhoradas, por meio da capacitação técnica dos responsáveis e por um trabalho constante de conscienti- zação em prol da garantia de qualidade dos alimentos produzidos.

\section{CONCLUSÕES}

Pelos resultados, constatou-se a necessidade de realização de avaliações microbiológicas periódicas nas linhas de processamento das unidades de alimentação e nutrição. A maioria do ar dos ambientes de processamento e das superfícies dos equipamentos e utensílios não atendeu às recomendações da APHA. Em relação às mãos dos manipuladores, constatou-se a ineficiência nos procedimentos de higienização pessoal. Além disso, há necessidade de definição de padrões ou recomendações mais adequados às condições brasileiras para o controle microbiológico nas unidades de alimentação e nutrição. Pelas condições microbiológicas encontradas nas unidades avaliadas, infere-se, numa fase inicial, a definição de metas a serem atingidas. Em etapas posteriores, essas unidades deverão atingir níveis de higiene mais exigentes, podendo, inclusive, adotar aqueles recomendados pela APHA.

\section{REFERÊNCIAS BIBLIOGRÁFICAS}

ANDRADE, N. J.; MACÊDO, J. A. B. Higienização na indústria de alimentos. São Paulo: Varela, 1996. $189 \mathrm{p}$.

ANDRADE, N. J.; DIAS, A. S.; CARELI, R. T. Elaboração e implantação de sistemas de higienização de microindústrias da região de Viçosa. In: SIMPÓSIO DE EXTENSÃO UNIVERSITÁRIA DA UFV, 1., 2000, Viçosa. Resumos... Viçosa: UFV, 2000. p. 37. 
ASSOCIAÇÃO BRASILEIRA DAS EMPRESAS DE REFEIÇÕES COLETIVAS - ABERC. Manual ABERC de práticas de elaboração e serviço de refeições coletivas. 2. ed. São Paulo, 1995. 109 p.

BRASIL. Resolução - RDC n. 12, 2 de janeiro de 2001. Estabelece padrões microbiológicos de alimentos. Agência Nacional de Vigilância Sanitária. Brasília: Ministério da Saúde, 2001.

BUZBY, J. C.; ROBERTS, T.; LIN, J. C. T.; MACDONALD, J. M. Bacterial foodborne disease: medical costs and productivity losses. [S.1.]: United States Department of Agriculture, 1996. 81 p. (Agricultural Economic Report, 741).

CARDOSO, R. C. V.; CHAVES, J. B. P.; ANDRADE, N. J.; TEIXEIRA, M. A. Avaliação da eficiência de agentes sanificantes para mãos de manipuladores de alimentos em serviços de refeição coletiva. Higiene Alimentar, São Paulo, v. 10, n. 41, p. 17-22, jan./fev. 1996.

FREITAS, L. H. Sistema especialista para diagnóstico de toxinfecções alimentares de origem bacteriana. 1995. 97 f. Dissertação (Mestrado em Ciência e Tecno- logia de Alimentos) - Universidade Federal de Viçosa, Viçosa.

GIRIOLI, M. A. Uma estratégia para avaliação da qualidade higiênico-sanitária de alimentos comercializados em serviços de alimentação. 1993. 124 f. Dissertação (Mestrado em Ciência de Alimentos) - Universidade Federal de Minas Gerais, Belo Horizonte.

HAZELWOOD, H. D. Manual de higiene para manipuladores de alimentos. São Paulo: Varela, 1994. 140 p.

SALUSTIANO, V. C.; BRABES, K. C. S.; ANDRADE, N. J. Ar de ambientes de processamento de um abatedouro: avaliação e controle por agentes químicos sanificantes. Revista Nacional da Carne, São Paulo, v. 25, n. 293, p. 154-152, 2001.

SVEUM, W. H.; MOBERG, L. J.; RUDE, R. A.; FRANK, J. F. Microbiological monitoring of the food processing environment. In: VANDERZANT, C.; SPLITTSTOESSER, D. F.; SPECK, M. L. (Eds.). Compendium of methods for the microbiological examination of foods. 3. ed. Washington: APHA, 1992. cap. 3, p. 51-74. 